Check for updates

Cite this: J. Mater. Chem. A, 2020, 8 , 1652

Received 16th October 2019 Accepted 8th January 2020

DOI: 10.1039/c9ta11408d

rsc.li/materials-a

\section{Oxygen vacancy engineering in spinel-structured nanosheet wrapped hollow polyhedra for electrochemical nitrogen fixation under ambient conditions $\uparrow$}

\author{
Feili Lai, ${ }^{\text {ac }}$ Jianrui Feng, ${ }^{a}$ Xiaobin Ye, ${ }^{c}$ Wei Zong, ${ }^{a}$ Guanjie He, (D)*b Chao Yang, ${ }^{d}$ \\ Wei Wang, (ID) ${ }^{d}$ Yue-E. Miao, (D) ${ }^{a}$ Bicai Pan, (D) ${ }^{c}$ Wensheng Yan, ${ }^{c}$ Tianxi Liu*a \\ and Ivan P. Parkin (D)*b
}

\begin{abstract}
Electrochemical nitrogen-to-ammonia conversion by the nitrogen reduction reaction (NRR) under ambient conditions is regarded as a potential approach to tackle the energy-intensive Haber-Bosch process with excessive $\mathrm{CO}_{2}$ emission. However, the NRR is still restricted by low faradaic efficiency and $\mathrm{NH}_{3}$ yield, which is due to the chemical inertness of $\mathrm{N}$-related groups for efficient adsorption/activation on the electrocatalysts. Here, a series of spinel-structured nanosheet wrapped hollow nitrogen-doped carbon polyhedra with abundant oxygen vacancies are constructed successfully. From theoretical aspects, these materials show increased charge density on their surface for enhanced capture and activation of $\mathrm{N}_{2}$ molecules. As a result, oxygen vacancy-rich $\mathrm{NiCO}_{2} \mathrm{O}_{4}$ on hollow $\mathrm{N}$-carbon polyhedra $\left(\mathrm{V}_{\mathrm{o}}\right.$-rich $\mathrm{NiCo}_{2} \mathrm{O}_{4}(\mathrm{aHNCP})$ shows outstanding electrocatalytic NRR performance with high production yield $\left(\mathrm{NH}_{3}: 4.1 \mu \mathrm{g} \mathrm{h}^{-1} \mathrm{~cm}^{-2} / 17.8 \mu \mathrm{g} \mathrm{h}^{-1} \mathrm{mg}^{-1}\right.$; faradaic efficiency: $5.3 \%$ ) and high stability under ambient conditions and is superior to the counterpart oxygen vacancy-poor electrocatalysts. Oxygen vacancy engineering introduces a new concept for rational design of advanced NRR catalysts for energy conversion systems.
\end{abstract}

\section{Introduction}

Ammonia $\left(\mathrm{NH}_{3}\right)$ is one of the most important carbon-free energy intermediates with low liquefying pressure and high

${ }^{a}$ State Key Laboratory for Modification of Chemical Fibers and Polymer Materials, College of Materials Science and Engineering, Innovation Center for Textile Science and Technology, Donghua University, Shanghai 201620, P. R. China. E-mail: txliu@ dhu.edu.cn

${ }^{b}$ Christopher Ingold Laboratory, Department of Chemistry, University College London, 20 Gordon Street, London WC1H OAJ, UK. E-mail: g.he@ucl.ac.uk; i.p.parkin@ucl.ac. $u k$

'Hefei National Laboratory for Physical Sciences at the Microscale, University of Science and Technology of China, Hefei, Anhui 230026, P. R. China

${ }^{d}$ Department of Materials Science and Engineering, College of Engineering, Peking University, Beijing 100871, P. R. China

$\dagger$ Electronic supplementary information (ESI) available: SEM, TEM, XRD, EDS, TGA, and XPS results, adsorptive properties of samples, XANES data, UV-Vis curves, electrochemical properties of samples, and theoretical calculations. See DOI: $10.1039 / \mathrm{c} 9 \mathrm{ta} 11408 \mathrm{~d}$ hydrogen density ${ }^{1,2}$ and is widely used in producing numerous chemicals, such as nitrogen fertilizers or pharmaceuticals, to satisfy the increasing demand from a booming world population..$^{3-5}$ Up to now, over $1 \%$ of the world's energy supply is used to produce ammonia by the traditional Haber-Bosch process which is responsible for $1.6 \%$ of global $\mathrm{CO}_{2}$ emissions and requires harsh operating conditions $\left(400-600^{\circ} \mathrm{C}\right.$ and $20-40$ $\mathrm{MPa}$ ) due to the chemical inertness of $\mathrm{N}_{2}$ with a high bond energy of $940.95 \mathrm{~kJ} \mathrm{~mol}^{-1} .{ }^{6-9}$ In contrast, the electrochemical $\mathrm{N}_{2}$ reduction reaction ( $\mathrm{NRR}, \mathrm{N}_{2}+6 \mathrm{H}^{+}+6 \mathrm{e}^{-} \rightarrow \mathrm{NH}_{3}$ ) occurs at ambient temperature and pressure and is regarded as a more sustainable and energy-efficient process for ammonia generation. ${ }^{10-14}$ Although some electrocatalysts have recently been investigated for the NRR, including noble metal electrocatalysts (such as $\mathrm{Ru}, \mathrm{Au}$, and $\mathrm{Rh}$ ), ${ }^{13-16}$ non-noble metal-based electrocatalysts (such as Fe-, Co-, and Mo-based materials), ${ }^{7,12,17,18}$ and conducting polymers (such as polyaniline and polypyrrole), ${ }^{19,20}$ their electrocatalytic properties are still limited by the low faradaic efficiency due to the confined electro-active sites in the corresponding bulk. ${ }^{10,11,21}$ Therefore, constructing multilevel nanostructures (such as one-dimensional nanofibers/nanotubes, ${ }^{22,23}$ two-dimensional ultrathin nanosheets, ${ }^{24,25}$ and threedimensional hollow nanostructures ${ }^{26,27}$ ) has become an efficient solution to obtain outstanding NRR electrocatalysts with a high specific surface area, thus resulting to an increased number of active sites for efficient reactant adsorption.

Apart from this, the impeded NRR process is deeply rooted in the chemical inertness of $\mathrm{N}_{2}$ molecules. Then, the question on how to capture and activate $\mathrm{N}_{2}$ gas much more efficiently using electrocatalysts arises. Atomic surface engineering (such as defect engineering ${ }^{28,29}$ and doping engineering ${ }^{30}$ ) is the best choice to regulate the electronic structure and alter the charge density distribution. Among various types of defects, the vacancy-type defect (such as oxygen vacancies) is regarded as a kind of point defect, which is caused by independent atoms escaping from the atomic surface. ${ }^{31-33}$ Up to now, several possible strategies have been discovered for generating oxygen vacancies in metal oxides, including chemical reduction, ${ }^{34}$ annealing in an oxygen poor atmosphere, ${ }^{35,36}$ and 
heterogeneous atom substitution. ${ }^{37}$ Furthermore, the oxygen vacancies created on the metal oxide surface could serve as trapping sites to capture and activate inert gas molecules of $\mathrm{N}_{2}$. However, to our knowledge, the proper control of the oxygen vacancy content in the electrocatalytic $\mathrm{N}_{2}$ reduction reaction is still in the rudimentary state.

To figure out the contribution of the oxygen vacancies in NRR applications, we conducted density functional theory (DFT) calculations by using $\mathrm{NiCo}_{2} \mathrm{O}_{4}$ with a perfect surface and oxygen vacancy-introduced surface as two models. As shown in Fig. 1, the introduction of oxygen vacancies in $\mathrm{NiCo}_{2} \mathrm{O}_{4}$ is beneficial for enhancing its stability towards $\mathrm{NNH}$ groups due to the presence of fewer coordination sites of Ni/Co cations around the vacancies. As further proved by the differential charge density of $\mathrm{NiCo}_{2} \mathrm{O}_{4}$ with oxygen vacancies, the bonded electrons can be delocalized to electron donors ( $\mathrm{Ni}$ and $\mathrm{Co}$ elements) near the oxygen vacancies and be activated dramatically. As a result, the $\mathrm{NiCo}_{2} \mathrm{O}_{4}$ with oxygen vacancies exhibits a lower stabilization energy of $0.30 \mathrm{eV}$ for $\mathrm{NNH}$ groups than $\mathrm{NiCo}_{2} \mathrm{O}_{4}$ with a perfect surface $(0.61 \mathrm{eV})$, indicating the positive role of oxygen vacancies in the following nitrogen reduction reactions. In addition, the delocalized electrons on the surface of $\mathrm{NiCo}_{2} \mathrm{O}_{4}$ with oxygen-vacancies are easier to excite to the conduction band, which is favorable not only for enhanced conductivity $^{35,38}$ but also for activation of $\mathrm{N}$-related groups, by transferring its electrons into their antibonding orbitals. At the same time, the hollow carbon polyhedron is beneficial not only for electron transfer from buried carbon to the oxygen vacancyrich $\mathrm{NiCo}_{2} \mathrm{O}_{4}$ surface for the fast NRR process, but also for increasing the number of active sites for the capture of $\mathrm{NNH}$ groups.

In this study, we design a series of highly efficient oxygen vacancy-rich spinel-structured nanosheets on hollow N-carbon polyhedra to facilitate the electrocatalytic $\mathrm{N}_{2}$ reduction reaction. Taking the oxygen vacancy-rich $\mathrm{NiCo}_{2} \mathrm{O}_{4}$ on hollow $\mathrm{N}$ carbon polyhedra $\left(V_{\mathrm{o}}\right.$-rich $\left.\mathrm{NiCo}_{2} \mathrm{O}_{4} @ \mathrm{HNCP}\right)$ as an example, it exhibited a high production yield $\left(\mathrm{NH}_{3}: 4.1 \mu \mathrm{g} \mathrm{h}^{-1} \mathrm{~cm}^{-2} / 17.8 \mu \mathrm{g}\right.$ $\mathrm{h}^{-1} \mathrm{mg}^{-1}$ and faradaic efficiency: $5.3 \%$ ), good selectivity at $-0.25 \mathrm{~V}$ versus RHE, and high stability during the NRR process and is much more outstanding than the corresponding oxygen vacancy-poor $\mathrm{NiCo}_{2} \mathrm{O}_{4}$ on hollow $\mathrm{N}$-carbon polyhedra $\left(V_{\mathrm{o}}\right.$-poor



Fig. 1 Schematic illustration of the stabilization of $\mathrm{NNH}$ groups on the $\mathrm{NiCO}_{2} \mathrm{O}_{4}$ with perfect and oxygen vacancy-introduced surfaces, as well as the partial charge density of $\mathrm{V}_{\mathrm{o}}$-rich $\mathrm{NiCO}_{2} \mathrm{O}_{4}$.
$\mathrm{NiCo}_{2} \mathrm{O}_{4} @ \mathrm{HNCP}$. Furthermore, this oxygen vacancy engineering can also be applied in other spinel-structured nanosheets (such as $\mathrm{ZnCo}_{2} \mathrm{O}_{4}$ and $\mathrm{Co}_{3} \mathrm{O}_{4}$ ), which leads to a general solution for the design of advanced NRR electrocatalysts.

\section{Results and discussion}

According to the theoretical work, oxygen vacancy-rich $\mathrm{NiCo}_{2} \mathrm{O}_{4}$ on hollow $\mathrm{N}$-carbon polyhedra ( $V_{\mathrm{o}}$-rich $\left.\mathrm{NiCo}_{2} \mathrm{O}_{4} @ \mathrm{HNCP}\right)$ was synthesized (Fig. S1 $\dagger$ ). As shown in Fig. 2a, the $V_{\mathrm{o}}$-rich $\mathrm{NiCo}_{2}-$ $\mathrm{O}_{4} @$ @NCP displays a regular geometrical shape with a maximum length of $\sim 850 \mathrm{~nm}$. A blurry interface between $\mathrm{HNCP}$ and $V_{\mathrm{O}}-\mathrm{NiCo}_{2} \mathrm{O}_{4}$ nanosheets can be observed in the corresponding HRTEM image (Fig. 2b), with mixed phases of amorphous carbon and crystalline $\mathrm{NiCo}_{2} \mathrm{O}_{4}$, which is beneficial for the charge accumulation and transfer. As a result, the two parts of HNCP and $V_{\mathrm{o}}$-rich $\mathrm{NiCo}_{2} \mathrm{O}_{4}$ nanosheets can be well connected with a shared electron transfer region. Meanwhile, the fringe spacing of $V_{\mathrm{o}}$-rich $\mathrm{NiCo}_{2} \mathrm{O}_{4}$ is revealed to be $\sim 0.23 \mathrm{~nm}$ in its HRTEM image (corresponding to the (311) plane), which demonstrates a negative role of oxygen vacancies in the crystalline $\mathrm{NiCo}_{2} \mathrm{O}_{4}$. As shown in the X-ray diffraction (XRD) pattern of $V_{\mathrm{o}}$-rich $\mathrm{NiCo}_{2} \mathrm{O}_{4} @ \mathrm{HNCP}$ (Fig. 2c), three typical peaks at $2 \theta=$ $36.9^{\circ}, 43.0^{\circ}$, and $62.7^{\circ}$ can be well indexed to the (311), (400) and (440) planes of spinel-structured $\mathrm{NiCo}_{2} \mathrm{O}_{4}$ (JCPDS card no. 731702), demonstrating its successful loading on the hollow nitrogen-doped carbon polyhedra. The nine-fold higher specific surface area $\left(82.1 \mathrm{~m}^{2} \mathrm{~g}^{-1}\right)$ of $V_{\mathrm{o}}$-rich $\mathrm{NiCo}_{2} \mathrm{O}_{4} @ H N C P$ compared to the $V_{\mathrm{o}}$-rich $\mathrm{NiCo}_{2} \mathrm{O}_{4}$ bulk $\left(9.0 \mathrm{~m}^{2} \mathrm{~g}^{-1}\right)$ (Fig. 2d) indicates its higher number of active sites, leading to shortened diffusion paths for reagents during the NRR process.

Further, for comparison, oxygen vacancy-poor $\mathrm{NiCo}_{2} \mathrm{O}_{4}$ on hollow N-carbon polyhedra $\left(V_{\mathrm{o}}\right.$-poor $\left.\mathrm{NiCo}_{2} \mathrm{O}_{4} @ H N C P\right)$ was obtained by calcining the corresponding nickel-cobalt layered double hydroxide nanosheet wrapped hollow nitrogen-doped carbon polyhedra (Ni-Co LDH@HNCP) in an oxygen atmosphere, and a series of characterization experiments was conducted (Fig. S2-S8†). In the $\mathrm{N}$ 1s X-ray photoelectron spectroscopy (XPS) spectrum (Fig. 2e), the peaks at $400.6 \mathrm{eV}$, $399.7 \mathrm{eV}$, and $398.7 \mathrm{eV}$ corresponded to the graphitic $\mathrm{N}$, pyrrolic $\mathrm{N}$, and pyridinic $\mathrm{N}$ of the HNCP template, which is beneficial for the efficient connection of both $V_{\mathrm{o}}$-rich and $V_{\mathrm{o}^{-}}$ poor $\mathrm{NiCo}_{2} \mathrm{O}_{4}$ nanosheets to form a charge-rich region. In addition, the nitrogen content was calculated to be $11.6 \mathrm{wt} \%$ (Fig. S9 $\dagger$ ). The binding energies of Co $2 \mathrm{p}_{3 / 2}(780 \mathrm{eV})$ and Co $2 \mathrm{p}_{1 / 2}$ $(795 \mathrm{eV})$ for $V_{\mathrm{o}}$-rich $\mathrm{NiCo}_{2} \mathrm{O}_{4} @ H N C P$ show negative shifts compared to those for $V_{\mathrm{o}}$-poor $\mathrm{NiCo}_{2} \mathrm{O}_{4} @ H N C P$ (Fig. 2f). This indicates that some $\mathrm{Co}^{3+}$ ions in the $\mathrm{NiCo}_{2} \mathrm{O}_{4}$ nanosheets are reduced to $\mathrm{Co}^{2+}$ after introduction of oxygen vacancies, ${ }^{39-42}$ due to the charge transfer from the $V_{\mathrm{o}}$ to the $\mathrm{Co}(\mathrm{Ni})^{3+}$ with a decreased number of $\mathrm{Co}(\mathrm{Ni})-\mathrm{O}$ bonds at the surfaces (Fig. S10 $\dagger$ ). In the O 1s XPS spectra (Fig. 2g), the peaks at 529.5, 531.1 and $532.5 \mathrm{eV}$ are associated with $\mathrm{Co}(\mathrm{Ni})-\mathrm{O}$ bonds (O1), oxygen vacancies or defects with lower oxygen coordination $(\mathrm{O} 2)$, and surface adsorbed water molecules (O3), respectively. ${ }^{43-45}$ The proportion of the integral-area of the $\mathrm{O} 2$ peak in $V_{\mathrm{o}}$-rich $\mathrm{NiCo}_{2} \mathrm{O}_{4} @ \mathrm{HNCP}$ is much larger than that in $V_{\mathrm{o}}$-poor 

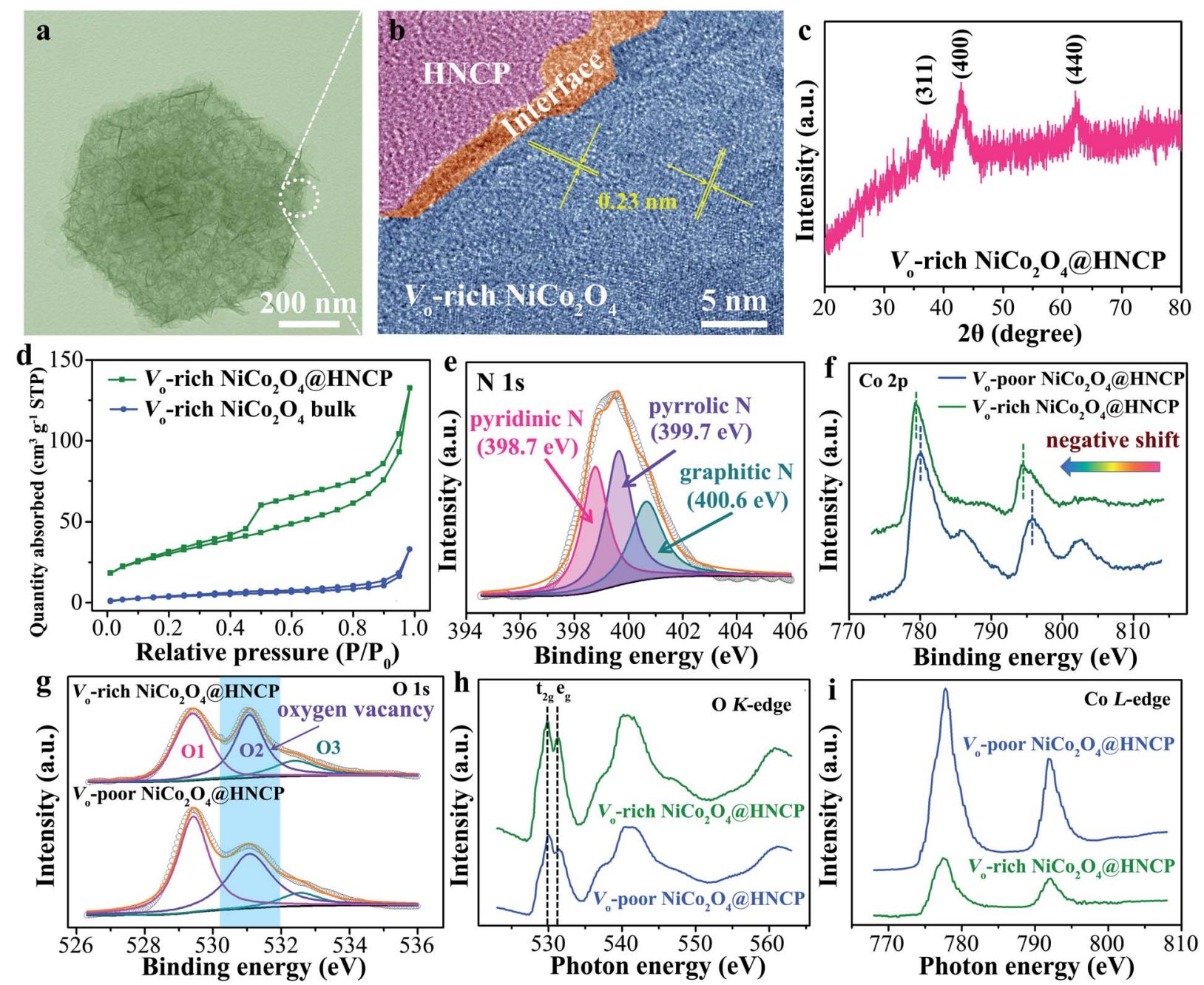

Fig. 2 (a) TEM and (b) HRTEM images of $V_{0^{\circ}}$-rich $\mathrm{NiCO}_{2} \mathrm{O}_{4}$ @HNCP. (c) XRD pattern of $V_{\mathrm{O}}$-rich $\mathrm{NiCO}_{2} \mathrm{O}_{4}$ (aHNCP. (d) $\mathrm{N}_{2}$ adsorption isotherms of $V_{\mathrm{O}^{-}}$ rich $\mathrm{NiCO}_{2} \mathrm{O}_{4}\left(\mathrm{aHNCP}\right.$ and the $V_{\mathrm{O}}$-rich $\mathrm{NiCO}_{2} \mathrm{O}_{4}$ bulk. (e) $\mathrm{N}$ 1s spectrum of $V_{\mathrm{o}}$-rich $\mathrm{NiCO}_{2} \mathrm{O}_{4} @ \mathrm{aHNCP}$. (f) Co $2 \mathrm{p}$ and (g) $\mathrm{O} 1 \mathrm{~s}$ spectra of $V_{\mathrm{O}}$-rich $\mathrm{NiCO}_{2} \mathrm{O}_{4} @ \mathrm{aHNCP}$ and $V_{\mathrm{o}}$-poor $\mathrm{NiCO}_{2} \mathrm{O}_{4}$ (aHNCP. (h) $\mathrm{O} \mathrm{K}$-edge and (i) Co L-edge XANES spectra of $V_{0}$-rich $\mathrm{NiCO}_{2} \mathrm{O}_{4} @ \mathrm{aHNCP}$ and $V_{\mathrm{O}}$-poor $\mathrm{NiCO}_{2} \mathrm{O}_{4}$ (aHNCP.

$\mathrm{NiCo}_{2} \mathrm{O}_{4} @ \mathrm{HNCP}$, indicating the successful introduction of abundant oxygen vacancies in $V_{\mathrm{o}}$-rich $\mathrm{NiCo}_{2} \mathrm{O}_{4} @ \mathrm{HNCP}^{35,39}$ In addition, the $V_{\mathrm{o}}(\mathrm{O} 2)$ proportion in $V_{\mathrm{o}}$-rich $\mathrm{NiCo}_{2} \mathrm{O}_{4} @ \mathrm{HNPC}$ increases from $33.0 \%$ to $68.2 \%$ as the annealing temperature increased from 200 to $300{ }^{\circ} \mathrm{C}$ (Fig. S11†), which means that the incorporated $V_{\mathrm{o}}$ amount can be well controlled by adjusting the annealing temperature. This finding could be further confirmed using the X-ray absorption near edge structure (XANES) of the O K-edge and Co L-edge. Fig. $2 \mathrm{~h}$ shows the $\mathrm{O}$ K-edge XANES spectra of $V_{\mathrm{o}}$-rich and $V_{\mathrm{o}}$-poor $\mathrm{NiCo}_{2} \mathrm{O}_{4} @ H N C P$ with two main folds. In the first fold at lower energy, another two sub-folds are centered at about 529.7 and $531.4 \mathrm{eV}$, which are denoted as $t_{2 g}$ and $\mathrm{e}_{\mathrm{g}}$ by the ligand field, respectively. A relatively high intense ratio of $\mathrm{e}_{\mathrm{g}}$ to $\mathrm{t}_{2 \mathrm{~g}}$ can be observed for $V_{\mathrm{o}}$-rich $\mathrm{NiCo}_{2} \mathrm{O}_{4} @ H N P C$, indicating the successful generation of abundant $V_{\mathrm{o}}$, which can be further proved in the magnified version of $t_{2 g}$ and $e_{g}$ at the $O$ K-edge (Fig. S12-S13†). Meanwhile, attributed to the Co $2 p$ to $3 d$ transition and spin-orbit coupling, the Co L-edge spectra can be split into two parts, L3-edge and L2-edge (Fig. 2i). ${ }^{\mathbf{4 6 , 4 7}}$ The lower peak intensity for both the Co L3-edge and L2-edge in $V_{\mathrm{o}}$-rich $\mathrm{NiCo}_{2} \mathrm{O}_{4} @ \mathrm{HNCP}$ indicates that more electrons would occupy the Co $3 \mathrm{~d}$ orbitals, providing more crucial evidence for the presence of abundant $V_{\mathrm{o}}$ on the surface of $V_{\mathrm{o}}$-rich $\mathrm{NiCo}_{2} \mathrm{O}_{4}$ @HNCP. A similar phenomenon is observed in the Ni L-edge spectrum (Fig. S14 $\dagger$ ). The generation of oxygen vacancies is due to the inadequate oxidation of $\mathrm{NiCo}_{2} \mathrm{O}_{4}$ in an oxygendeficient atmosphere as compared to an oxygen atmosphere, leading to abundant partially unoxidized metal domains in the $\mathrm{NiCo}_{2} \mathrm{O}_{4}$ structure. ${ }^{48,49}$

To reveal the role of oxygen vacancies in tuning the electronic structures of the $\mathrm{NiCo}_{2} \mathrm{O}_{4}$ nanosheets, DFT calculations were performed for different types of oxygen vacancies. Considering that there are two types of oxygen (e.g. surface and sub-surface oxygens) in the perfect crystallographic lattice of $\mathrm{NiCo}_{2} \mathrm{O}_{4}$ (Fig. 3a), we separately studied each situation regarding their density of states, formation possibility and adsorption ability towards the key NRR intermediates of $\mathrm{NNH}$ groups. The surface oxygen was removed first for building the 

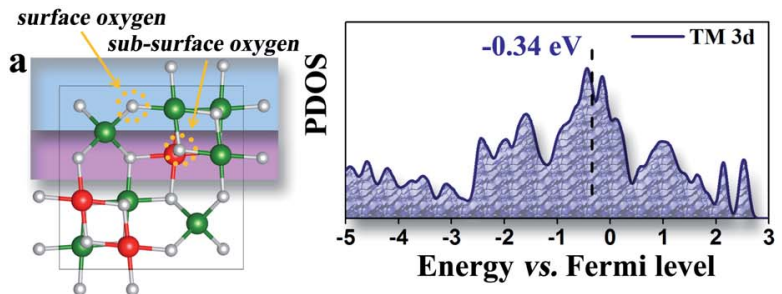

b


Energy vs. Fermi level
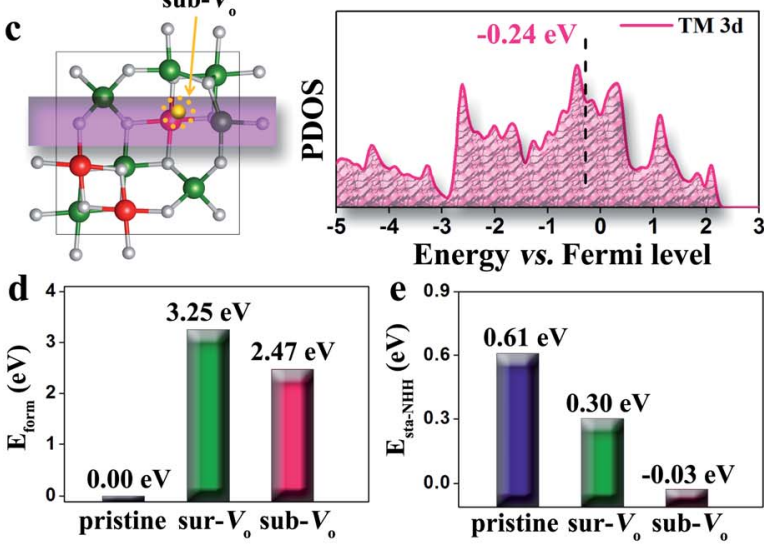

Fig. 3 (a) Pristine $\mathrm{NiCO}_{2} \mathrm{O}_{4}$ structure and projected density of states (PDOS) of the surface transition metal. (b) The defect model with removal of a surface oxygen vacancy (sur- $V_{\mathrm{o}}$ ) and its PDOS. (c) The defect model with removal of a sub-surface oxygen vacancy (sub- $V_{0}$ ) and its PDOS. (d) The formation energy of oxygen vacancies for the three catalyst models. (e) Adsorption energy of $\mathrm{NNH}$ groups in the three catalyst models.

surface oxygen vacancy (sur- $V_{\mathrm{o}}$ ) model, as shown in Fig. 3b. We found that the d-band center of the sur- $V_{\mathrm{o}}$ model is $-0.28 \mathrm{eV}$, much closer to the Fermi level compared with that of the pristine $\mathrm{NiCo}_{2} \mathrm{O}_{4}$ model $(-0.34 \mathrm{eV})$. This result indicates that oxygen vacancies can induce more activity of the metal atoms, that is, the adsorption strength of molecules and radicals over the metal atoms will be enhanced. As shown in Fig. 3c, we tested another type of oxygen vacancy, the sub-surface oxygen vacancy (sub- $\left.V_{\mathrm{o}}\right)$ model, which has the closest d-band center $(-0.24 \mathrm{eV})$ to the Fermi level among the three models. In the subsequent calculation, we found that the possibility of the formation of these two types of oxygen vacancies is not the same (Fig. 3d). As a more positive formation energy denotes that a vacancy is more difficult to form, the results show that sub- $V_{\mathrm{o}}(2.47 \mathrm{eV})$ has a higher stability than sur- $V_{\mathrm{o}}(3.25 \mathrm{eV})$. Finally, we calculated the adsorption strength of the three models by using $\mathrm{NNH}$ as a probe and found that the sub- $V_{\mathrm{o}}$ model presents the most favorable energy $(-0.03 \mathrm{eV})$. The adsorption energy of the sur- $V_{\mathrm{o}}$ $(0.30 \mathrm{eV})$ is also more negative than that of the pristine model (0.61 eV), indicating its enhanced adsorption ability, which is consistent with the d-band center results. According to the trend of formation energy, we can deduce that the sub- $V_{\mathrm{o}}$ is preferentially formed when the vacancy density is relatively low. Therefore, the adsorption enhancement will be significantly dependent on the vacancy density in the region of low vacancy density.

To illustrate the role of oxygen vacancies in the NRR, a twocompartment cell was assembled by employing $V_{\mathrm{o}}$-rich $\mathrm{NiCo}_{2}$ $\mathrm{O}_{4} @ \mathrm{HNCP}$ as the cathode catalyst with continuous $\mathrm{N}_{2}$ bubbling in a $0.1 \mathrm{M} \mathrm{Na}_{2} \mathrm{SO}_{4}$ electrolyte. The highest average yields and corresponding faradaic efficiencies of $V_{\mathrm{o}}$-rich $\mathrm{NiCo}_{2} \mathrm{O}_{4} @ \mathrm{HNCP}$ are achieved when the negative potential increases to $-0.25 \mathrm{~V}$ versus the reversible hydrogen electrode (RHE) and are calculated to be about $4.1 \mu \mathrm{g} \mathrm{h}^{-1} \mathrm{~cm}^{-2} / 17.8 \mu \mathrm{g} \mathrm{h}^{-1} \mathrm{mg}^{-1}$ and $5.3 \%$, respectively (Fig. $4 \mathrm{a}$ and $\mathrm{S} 15 \dagger$ ). This production yield at $-0.25 \mathrm{~V}$ is also confirmed by the nuclear magnetic resonance (NMR) method as shown in Fig. S16-S18 and Table S1. $\dagger$ Beyond this negative potential, the $\mathrm{NH}_{3}$ yields and faradaic efficiencies decrease significantly because of the overwhelming competition from the hydrogen evolution reaction (HER). The NRR performance of the $V_{\mathrm{o}}$-rich $\mathrm{NiCo}_{2} \mathrm{O}_{4} @ \mathrm{HNCP}$ catalyst is much more outstanding than that of the $V_{\mathrm{o}}$-poor $\mathrm{NiCo}_{2} \mathrm{O}_{4} @ H N C P$ catalyst $\left(1.6 \mu \mathrm{g} \mathrm{h}^{-1} \mathrm{~cm}^{-2} / 6.9 \mu \mathrm{g} \mathrm{h}^{-1} \mathrm{mg}^{-1}\right.$ and $1.8 \%$ at $\left.-0.25 \mathrm{~V}\right)$, as well as other results under ambient conditions or at high temperatures and pressures (Table $\mathrm{S} 2 \dagger$ ). Note that no hydrazine is detected in the electrolyte (Fig. S19 $\dagger$ ). In addition, the charge amounts of the experimentally quantified $\mathrm{NH}_{3}$ and $\mathrm{H}_{2}$ gases and the calculated one (Fig. $\mathrm{S} 20^{\dagger}$ ) are roughly in agreement (S2 $\approx \mathrm{S} 3$ ). These results indicate the high selectivity of the $V_{\mathrm{o}}$-rich $\mathrm{NiCo}_{2} \mathrm{O}_{4} @ \mathrm{HNCP}$ catalyst for $\mathrm{NH}_{3}$ generation except for $\mathrm{H}_{2}$ gas. For practical use, stability is another critical criterion to evaluate the NRR performance of a catalyst. As shown in Fig. 4 b and $\mathrm{S} 21-26, \uparrow$ the $\mathrm{NH}_{3}$ yield, faradaic efficiency, and current density of the $V_{\mathrm{o}}$-rich $\mathrm{NiCo}_{2} \mathrm{O}_{4} @ \mathrm{HNCP}$ catalyst are all stable without obvious fluctuation. As shown in Fig. S27, $\dagger$ the $V_{\mathrm{o}}$-rich $\mathrm{NiCo}_{2}-$ $\mathrm{O}_{4} @ \mathrm{HNCP}$ catalyst displays ultra-stable properties in both $\mathrm{NH}_{3}$ yield and faradaic efficiency even after working for $100 \mathrm{~h}$ and is comparable to the recently reported catalysts but with a much longer practical life. ${ }^{50}$ By using XRD and XPS analyses (Fig. S28 $\dagger$ ), the $V_{\mathrm{o}}$-rich $\mathrm{NiCo}_{2} \mathrm{O}_{4} @ H N C P$ catalyst is found to exhibit an unchanged crystal structure and only slightly decreased oxygen vacancy content after working for $100 \mathrm{~h}$, which demonstrates the relatively stable structure of $V_{\mathrm{o}}$-rich $\mathrm{NiCo}_{2} \mathrm{O}_{4} @ \mathrm{HNCP}$ as an NRR catalyst. Due to the similar results of $\mathrm{NH}_{3}$ yield and faradaic efficiency after varying the nitrogen flow rate at $-0.25 \mathrm{~V}$ (Fig. $4 \mathrm{c}$ ), the $\mathrm{N}_{2}$ diffusion process becomes a non-rate-determining step as it is an independent gas-solid interface. Moreover, by varying the reaction temperature of the $\mathrm{NRR}$, both the $\mathrm{NH}_{3}$ yield and faradaic efficiency of the $V_{\mathrm{o}}$-rich $\mathrm{NiCo}_{2} \mathrm{O}_{4} @ \mathrm{HNCP}$ catalyst increase simultaneously (Fig. 4d). For instance, the NRR yield is about 2.5 times higher at $60{ }^{\circ} \mathrm{C}$ than at $0{ }^{\circ} \mathrm{C}$, indicating that mass transfer plays a key role in enhancing the reaction rate of the $V_{\mathrm{o}}$-rich $\mathrm{NiCo}_{2} \mathrm{O}_{4} @ \mathrm{HNCP}$ catalyst. In accordance with the Arrhenius equation and Arrhenius plot (Fig. S29 $\dagger$ ), the apparent activation energy of $V_{\mathrm{o}^{-}}$ rich $\mathrm{NiCo}_{2} \mathrm{O}_{4} @ \mathrm{HNCP}$ for the $\mathrm{NRR}$ is calculated to be $11.4 \mathrm{~kJ} \mathrm{~mol}^{-1}$. The UV/Vis absorption spectra of various samples (Fig. 4e) and photographs of $\mathrm{NH}_{4}{ }^{+}$-containing solutions before 

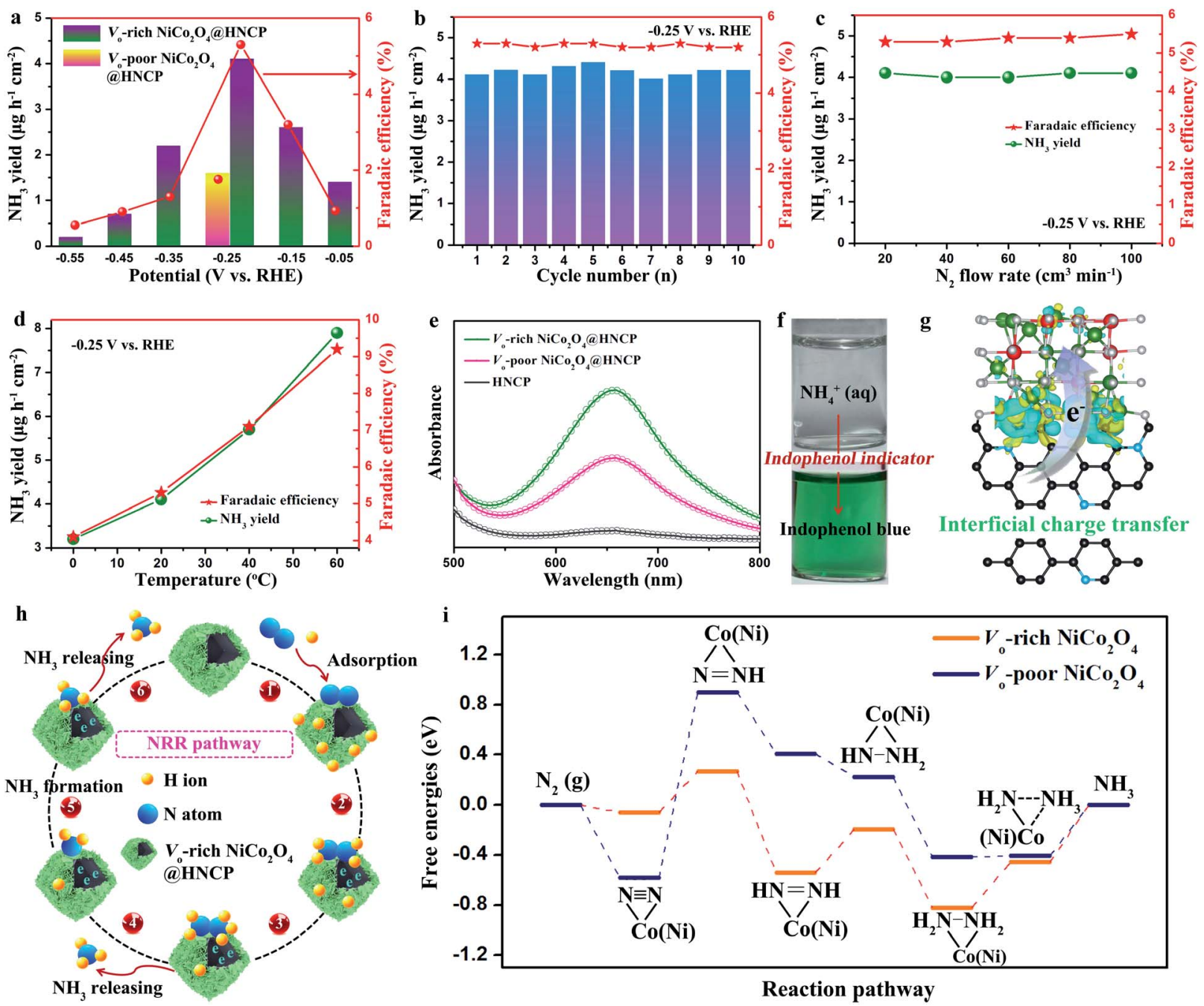

Fig. 4 Electrocatalytic NRR of $V_{\circ}$-rich and $V_{\circ}$-poor $\mathrm{NiCO}_{2} \mathrm{O}_{4}$ (aHNCP in an aqueous solution of $0.1 \mathrm{M} \mathrm{Na}_{2} \mathrm{SO}_{4}$ under ambient conditions. (a) Yield of $\mathrm{NH}_{3}$ (bar graph) and faradaic efficiency (red) at each given potential. (b) Recycling test of $\mathrm{V}_{\mathrm{O}}$-rich $\mathrm{NiCO}_{2} \mathrm{O}_{4} \mathrm{QHNCP}_{\mathrm{HN}}$ a potential of $-0.25 \mathrm{~V}$. Yield rate of $\mathrm{NH}_{3}$ (green) and faradaic efficiency at different (c) $\mathrm{N}_{2}$ flow rates and (d) temperatures at $-0.25 \mathrm{~V}$. (e) UV-Vis absorption spectra of various samples after chronoamperometry testing at $-0.25 \mathrm{~V}$ versus $\mathrm{RHE}$. (f) $\mathrm{NH}_{4}^{+}$-containing solution stained with indophenol indicator. (g) Charge density distribution of $\mathrm{V}_{\mathrm{O}}$-rich $\mathrm{NiCO}_{2} \mathrm{O}_{4} \mathrm{aHNCP}$ around the interface and oxygen vacancy. (h) Schematic illustration of the proposed electrochemical NRR pathway by using the $\mathrm{V}_{\mathrm{o}}$-rich $\mathrm{NiCO}_{2} \mathrm{O}_{4}$ (aHNCP catalyst. (i) Free energy diagram of the electrochemical reduction of $\mathrm{N}_{2}$ to $\mathrm{NH}_{3}$ in an alternating pathway on the surface of the $\mathrm{V}_{\mathrm{o}}$-rich $\mathrm{NiCO}_{2} \mathrm{O}_{4}$ (aHNCP catalyst.

and after staining with indophenol indicator (Fig. 4f) are exhibited. After comparing the EIS spectra (Fig. S30 $\dagger$ ) and the performance of the $V_{\mathrm{o}}$-rich $\mathrm{NiCo}_{2} \mathrm{O}_{4}$ bulk $\left(1.4 \mu \mathrm{g} \mathrm{h}^{-1} \mathrm{~cm}^{-2} / 6.1\right.$ $\mu \mathrm{g} \mathrm{h} \mathrm{h}^{-1} \mathrm{mg}^{-1}$ and $1.6 \%$ at $-0.25 \mathrm{~V}$ ) in Fig. S31, $\dagger$ it could be seen that the hollow nitrogen-doped carbon polyhedron template in $V_{\mathrm{o}}$-rich $\mathrm{NiCo}_{2} \mathrm{O}_{4} @ \mathrm{HNCP}$ is extremely vital for its enhanced NRR performance, due to the increased specific surface area (Fig. 2d) and well-formed interface between HNCP and $V_{\mathrm{o}}$-rich $\mathrm{NiCo}_{2} \mathrm{O}_{4}$ nanosheets for charge accumulation/transfer. For the verification of the source of ammonia, a ${ }^{15} \mathrm{~N}$ isotope labeling experiment using NMR (600 MHz) was performed. As shown in Fig. S32, $\dagger$ the ${ }^{1} \mathrm{H}$ NMR signals of ${ }^{14} \mathrm{NH}_{4}{ }^{+}$produced ${ }^{14} \mathrm{~N}$ triplets in the region of 6.8-7.1 ppm. Importantly, the ${ }^{1} \mathrm{H}$ NMR signal of ${ }^{15} \mathrm{NH}_{4}{ }^{+}$only produced an ${ }^{15} \mathrm{~N}$ doublet without the appearance of ${ }^{14} \mathrm{~N}$ triplets in the same region, which demonstrates that the doped nitrogen atoms in the HNCP template are stable and do not escape from the structures. Therefore, the source of ammonia is the feed $\mathrm{N}_{2}$ gas rather than the electrocatalyst.

For further detailed insights into the structure-activity relationship between the $V_{\mathrm{o}}$-rich $\mathrm{NiCo}_{2} \mathrm{O}_{4} @ \mathrm{HNCP}$ catalyst and its enhanced NRR properties, DFT calculation was carried out from the perspective of thermodynamic and kinetic acceleration. First, from the thermodynamic point of view, the electrons that previously occupied the $\mathrm{O} 2 \mathrm{p}$ orbital would partially delocalized to the neighboring $\mathrm{Ni} / \mathrm{Co}$ cations after introduction of oxygen vacancies, which suggests that a surface with oxygen vacancies is much more activated. Meanwhile, a rational model for the $V_{\mathrm{o}^{-}}$ rich $\mathrm{NiCo}_{2} \mathrm{O}_{4} @ \mathrm{HNCP}$ catalyst was constructed by aligning optimized $V_{\mathrm{o}}$-rich $\mathrm{NiCo}_{2} \mathrm{O}_{4}$ with highly conductive nitrogendoped carbon (Fig. $4 \mathrm{~g}$ and $\mathrm{S} 33 \dagger$ ). After analysis in detail, 
abundant charges accumulated on the blurry interface between $V_{\mathrm{o}}$-rich $\mathrm{NiCo}_{2} \mathrm{O}_{4}$ and nitrogen-doped carbon, leading to the successful generation of highly active regions for the electrocatalytic process. As shown in Fig. S34 and S35, $\uparrow$ the electrons are prone to transfer from nitrogen-doped carbon to $V_{\mathrm{o}}$-rich $\mathrm{NiCo}_{2} \mathrm{O}_{4}$ due to their inconsistent charge distribution. In turn, the Ni/Co cations show increased electronic states of the dorbital around the Fermi level, which is beneficial for activation of $\mathrm{N}_{2}$ and formation of an N-catalyst bond. From the kinetic point of view, the hollow nitrogen-doped carbon polyhedron template endows the $V_{\mathrm{o}}$-rich $\mathrm{NiCo}_{2} \mathrm{O}_{4}$ nanosheets with a higher specific surface area with more exposed active sites for adsorption/activation of $\mathrm{N}$-related species. Attributed to the structural merits of the $V_{\mathrm{o}}$-rich $\mathrm{NiCo}_{2} \mathrm{O}_{4} @ H N C P$ catalyst, a possible NRR mechanism is depicted in Fig. $4 \mathrm{~h}$ and i. Firstly, the $\mathrm{N}_{2}$ gas can be easily adsorbed on the surface of the $V_{\mathrm{o}}$-rich $\mathrm{NiCo}_{2} \mathrm{O}_{4} @ \mathrm{HNCP}$ catalyst to form chemisorbed $\mathrm{Co}(\mathrm{Ni})-\mathrm{N}_{2}$ bonds, which can be denoted as $\mathrm{N}_{2}(\mathrm{~g}) \rightarrow \mathrm{N}_{2}^{*}$ (here, the asterisk * denotes an adsorption site). After full structural relaxation, two energetically favorable configurations were found: end-on and side-on. On the $V_{\mathrm{o}}$-poor $\mathrm{NiCo}_{2} \mathrm{O}_{4}$ surface, an $\mathrm{N}_{2}$ molecule was more likely to anchor in the end-on configuration with a $\mathrm{Co}-\mathrm{N}$ bond length of $1.84 \AA$ (Fig. S36a $\dagger$ ), whereas, on the $V_{\mathrm{o}}$-rich $\mathrm{NiCo}_{2} \mathrm{O}_{4}$ surface, two Co-N bonds (1.20 $\AA$ in length) in the sideon configuration are formed with an elongated $\mathrm{N}-\mathrm{N}$ bond length from $1.12 \AA$ to $1.16 \AA$ (Fig. S36b $\dagger$ ). When taking $\Delta E_{\mathrm{ZPE}}$ and entropy into consideration, the $\Delta G$ values for $\mathrm{N}_{2}$ adsorption are $-0.05 \mathrm{eV}$ for the $V_{\mathrm{o}}$-rich $\mathrm{NiCo}_{2} \mathrm{O}_{4}$ surface and $-0.57 \mathrm{eV}$ for the $V_{\mathrm{o}}$-poor $\mathrm{NiCo}_{2} \mathrm{O}_{4}$ surface, respectively. Secondly, six consecutive protonation and reduction processes on the $V_{\mathrm{o}^{-}}$ rich(poor) $\mathrm{NiCo}_{2} \mathrm{O}_{4}$ surfaces were further proposed with atomic configurations at various states of each elementary step (Fig. S37†). As discussed in Fig. $4 \mathrm{i}$ and Table $\mathrm{S} 3, \dagger$ the free energies of all these states were slightly downhill for the $V_{\mathrm{o}}$-rich $\mathrm{NiCo}_{2} \mathrm{O}_{4}$ surface compared to the $V_{\mathrm{o}}$-poor $\mathrm{NiCo}_{2} \mathrm{O}_{4}$ surface, which also proves that the successful introduction of oxygen vacancies in $\mathrm{NiCo}_{2} \mathrm{O}_{4}$ is beneficial for the nitrogen reduction reaction process theoretically.

We further studied the NRR activity of other spinel-structured nanosheet wrapped $\mathrm{HNCP}$, such as $\mathrm{ZnCo}_{2} \mathrm{O}_{4} @ \mathrm{HNCP}$ and $\mathrm{Co}_{3}$ $\mathrm{O}_{4} @ H N C P$, in which oxygen vacancies were deliberately introduced. It should be noted that the XPS O 1s spectra (Fig. S38 $\dagger$ ) reveal that abundant oxygen vacancies were successfully introduced into the surface of both the $V_{\mathrm{o}}$-rich ZnCo@HNCP and $V_{\mathrm{o}^{-}}$ rich Co@HNCP catalysts. As shown in Fig. 5a, all the catalysts with abundant oxygen vacancies showed a higher $\mathrm{NH}_{3}$ yield rate and faradaic efficiency than their $V_{\mathrm{o}}$-poor counterparts in $0.1 \mathrm{M}$ $\mathrm{Na}_{2} \mathrm{SO}_{4}$. Taking $V_{\mathrm{o}}$-rich ZnCo@HNCP and its $V_{\mathrm{o}}$-poor counterpart as examples, the $\mathrm{NH}_{3}$ yield rate and faradaic efficiency for the $V_{\mathrm{o}}$-rich ZnCo@HNCP catalyst were $3.7 \mu \mathrm{g} \mathrm{h} \mathrm{h}^{-1} \mathrm{~cm}^{-2} / 16.0 \mu \mathrm{g}$ $\mathrm{h}^{-1} \mathrm{mg}^{-1}$ and $3.6 \%$, respectively, which are much more outstanding than those of the $V_{\mathrm{o}}$-poor ZnCo@HNCP catalyst (1.6 $\mu \mathrm{g} \mathrm{h}^{-1} \mathrm{~cm}^{-2} / 6.9 \mu \mathrm{g} \mathrm{h}^{-1} \mathrm{mg}^{-1}$ and $1.7 \%$ at $\left.-0.25 \mathrm{~V}\right)$. Besides, the time-dependent curves of various catalysts at $-0.25 \mathrm{~V}$ (Fig. $5 \mathrm{~b}$ ) exhibited excellent stability, indicating the stable vacancy structure in both the $V_{\mathrm{o}}$-rich ZnCo@HNCP and $V_{\mathrm{o}}$-rich Co@HNCP catalysts during the NRR process.


Fig. 5 (a) Average $\mathrm{NH}_{3}$ yields and faradaic efficiency of other spinelstructured nanosheet wrapped HNCP (ZnCo@HNCP and Co@HNCP) with and without oxygen vacancies after chronoamperometry testing at $-0.25 \mathrm{~V}$ versus RHE. (b) Time-dependent current density curves of various catalysts for the NRR at $-0.25 \mathrm{~V}$ versus $\mathrm{RHE}$.

\section{Conclusions and outlook}

In summary, we uncovered the positive role of oxygen vacancies in spinel-structured nanosheets on hollow $\mathrm{N}$-carbon polyhedra (e.g. $V_{\mathrm{o}}$-rich $\mathrm{NiCo}_{2} \mathrm{O}_{4} @ \mathrm{HNCP}, V_{\mathrm{o}}$-rich $\mathrm{ZnCo}_{2} \mathrm{O}_{4} @ H N C P$, and $V_{\mathrm{o}^{-}}$ rich $\left.\mathrm{Co}_{3} \mathrm{O}_{4} @ \mathrm{HNCP}\right)$ towards the electrocatalysis of the nitrogen reduction reaction. For example, the $V_{\mathrm{o}}$-rich $\mathrm{NiCo}_{2} \mathrm{O}_{4} @ \mathrm{HNCP}$ catalyst showed higher production yield $\left(\mathrm{NH}_{3}: 4.1 \mu \mathrm{g} \mathrm{h} \mathrm{h}^{-1} \mathrm{~cm}^{-2}\right.$ / $17.8 \mu \mathrm{g} \mathrm{h}^{-1} \mathrm{mg}^{-1}$ and faradaic efficiency: $5.3 \%$ ), good selectivity and high stability when compared with its $V_{\mathrm{o}}$-poor counterpart $\left(\mathrm{NH}_{3}: 1.6 \mu \mathrm{g} \mathrm{h}^{-1} \mathrm{~cm}^{-2} / 6.9 \mu \mathrm{g} \mathrm{h}^{-1} \mathrm{mg}^{-1}\right.$ and faradaic efficiency: $1.8 \%)$. As revealed by DFT calculations, the oxygen vacancies enhance the reactivity of the active sites, leading to reduced stabilization energy of NNH groups. Meanwhile, the HNCP template increased the number of active sites for facilitating the reaction on the surface of $V_{\mathrm{o}}$-rich $\mathrm{NiCo}_{2} \mathrm{O}_{4}$ nanosheets and improved the conductivity for interfacial electron transfer between $V_{\mathrm{o}}$-rich $\mathrm{NiCo}_{2} \mathrm{O}_{4}$ and $\mathrm{HNCP}$. Systematic study from both theoretical and experimental aspects further confirmed the superior kinetics for $\mathrm{NH}_{3}$ production using $V_{\mathrm{O}}$-rich $\mathrm{NiCo}_{2}$ $\mathrm{O}_{4} @$ @HNCP. Therefore, this work provides a guideline for the rational design of novel and highly efficient catalysts towards $\mathrm{N}_{2}$ electrochemical reduction by increasing the surface area and introducing surface oxygen vacancies in spinel-structured nanosheets simultaneously.

\section{Experimental section}

Details of the synthetic procedures, characterization and theoretical calculation methods can be found in the ESI $\dagger$.

\section{Conflicts of interest}

The authors declare no conflict of interest.

\section{Acknowledgements}

We are very grateful for the financial support from the National Natural Science Foundation of China (51433001, 21674019, and 21604010), the Science and Technology Commission of Shanghai Municipality (16520722100), the Program of Shanghai Academic Research Leader (17XD1400100), the "Chenguang Program" supported by the Shanghai Education Development 
Foundation and Shanghai Municipal Education Commission (16CG39) and the Engineering and Physical Sciences Research Council (EPSRC, EP/L015862/1). The computational center of the USTC is acknowledged for computational support.

\section{References}

1 T. Spatzal, K. A. Perez, O. Einsle, J. B. Howard and D. C. Rees, Science, 2014, 345, 1620-1623.

2 R. Lan, J. Irvine and S. W. Tao, Int. J. Hydrogen Energy, 2012, 37, 1482-1492.

3 K. A. Brown, D. F. Harris, M. B. Wilker, A. Rasmussen, N. Khadka, H. Hamby, S. Keable, G. Dukovic, J. W. Peters, L. C. Seefeldt and P. W. King, Science, 2016, 352, 448-450.

4 B. M. Hoffman, D. Lukoyanov, Z. Y. Yang, D. R. Dean and L. C. Seefeldt, Chem. Rev., 2014, 114, 4041-4062.

5 V. Rosca, M. Duca, M. T. de Groot and M. Koper, Chem. Rev., 2009, 109, 2209-2244.

6 M. Kitano, Y. Inoue, Y. Yamazaki, F. Hayashi, S. Kanbara, S. Matsuishi, T. Yokoyama, S. W. Kim, M. Hara and H. Hosono, Nat. Chem., 2012, 4, 934-940.

7 S. Kuriyama, K. Arashiba, K. Nakajima, Y. Matsuo, H. Tanaka, K. Ishii, K. Yoshizawa and Y. Nishibayashi, Nat. Commun., 2016, 7, 12181.

8 M. Ali, F. L. Zhou, K. Chen, C. Kotzur, C. L. Xiao, L. Bourgeois, X. Y. Zhang and D. R. MacFarlane, Nat. Commun., 2016, 7, 11335.

9 Y. H. Lu, Y. Yang, T. F. Zhang, Z. Ge, H. C. Chang, P. S. Xiao, Y. Y. Xie, L. Hua, Q. Y. Li, H. Y. Li, B. Ma, N. J. Guan, Y. F. Ma and Y. S. Chen, ACS Nano, 2016, 10, 10507-10515.

10 C. X. Guo, J. R. Ran, A. Vasileff and S. Z. Qiao, Energy Environ. Sci., 2018, 11, 45-56.

11 G. F. Chen, X. R. Cao, S. Q. Wu, X. Y. Zeng, L. X. Ding, M. Zhu and H. H. Wang, J. Am. Chem. Soc., 2017, 139, 9771-9774.

12 Y. Nishibayashi, Inorg. Chem., 2015, 54, 9234-9247.

13 S. J. Li, D. Bao, M. M. Shi, B. R. Wulan, J. M. Yan and Q. Jiang, Adv. Mater., 2017, 29, 170000133.

14 M. M. Shi, D. Bao, B. R. Wulan, Y. H. Li, Y. F. Zhang, J. M. Yan and Q. Jiang, Adv. Mater., 2017, 29, 160655017.

15 V. Kordali, G. Kyriacou and C. Lambrou, Chem. Commun., 2000, 1673-1674.

16 H. M. Liu, S. H. Han, Y. Zhao, Y. Y. Zhu, X. L. Tian, J. H. Zeng, J. X. Jiang, B. Y. Xia and Y. Chen, J. Mater. Chem. A, 2018, 6, 3211-3217.

17 K. Arashiba, E. Kinoshita, S. Kuriyama, A. Eizawa, K. Nakajima, H. Tanaka, K. Yoshizawa and Y. Nishibayashi, J. Am. Chem. Soc., 2015, 137, 5666-5669.

18 S. Kuriyama, K. Arashiba, H. Tanaka, Y. Matsuo, K. Nakajima, K. Yoshizawa and Y. Nishibayashi, Angew. Chem. Int. Ed., 2016, 55, 14291-14295; Angew. Chem., 2016, 128, 14503-14507.

19 F. Koleli and D. B. Kayan, J. Electroanal. Chem., 2010, 638, 119-122.

20 F. Koleli and T. Ropke, Appl. Catal., B, 2006, 62, 306-310.

21 R. Lan, J. Irvine and S. W. Tao, Sci. Rep., 2013, 3, 1145.

22 F. L. Lai, D. Y. Yong, X. L. Ning, B. C. Pan, Y. E. Miao and T. X. Liu, Small, 2017, 13, 16028667.
23 F. X. Ma, L. Yu, C. Y. Xu and X. W. Lou, Energy Environ. Sci., 2016, 9, 862-866.

24 S. C. Chen, Z. X. Kang, X. Hu, X. D. Zhang, H. Wang, J. F. Xie, X. S. Zheng, W. S. Yan, B. C. Pan and Y. Xie, Adv. Mater., 2017, 29, 170168730.

25 J. Q. Xu, X. D. Li, W. Liu, Y. F. Sun, Z. Y. Ju, T. Yao, C. M. Wang, H. X. Ju, J. F. Zhu, S. Q. Wei and Y. Xie, Angew. Chem. Int. Ed., 2017, 56, 9121-9125; Angew. Chem., 2017, 129, 9249-9253.

26 B. Y. Guan, S. L. Zhang and X. W. Lou, Angew. Chem. Int. Ed., 2018, 57, 6176-6180; Angew. Chem., 2018, 130, 6284-6288.

27 L. Yu, J. F. Yang, B. Y. Guan, Y. Lu and X. W. Lou, Angew. Chem. Int. Ed., 2018, 57, 172-176; Angew. Chem., 2018, 130, 178-182.

28 Y. Tong, Y. Q. Guo, K. J. Mu, H. Shan, J. Dai, Y. Liu, Z. Sun, A. D. Zhao, X. C. Zeng, C. Z. Wu and Y. Xie, Adv. Mater., 2017, 29, 1703123.

29 J. F. Xie and Y. Xie, ChemCatChem, 2015, 7, 2568-2580.

30 Y. Shi, Y. Zhou, D. R. Yang, W. X. Xu, C. Wang, F. B. Wang, J. J. Xu, X. H. Xia and H. Y. Chen, J. Am. Chem. Soc., 2017, 139, 15479-15485.

31 A. R. Singh, B. A. Rohr, J. A. Schwalbe, M. Cargnello, K. Chan, T. F. Jaramillo, I. Chorkendorff and J. K. Norskov, ACS Catal., 2017, 7, 706-709.

32 C. van der Ham, M. Koper and D. Hetterscheid, Chem. Soc. Rev., 2014, 43, 5183-5191.

33 H. K. Lee, C. Koh, Y. H. Lee, C. Liu, I. Y. Phang, X. M. Han, C. K. Tsung and X. Y. Ling, Sci. Adv., 2018, 4, eaar32083.

34 S. J. Peng, F. Gong, L. L. Li, D. S. Yu, D. X. Ji, T. R. Zhang, Z. Hu, Z. Q. Zhang, S. L. Chou, Y. H. Du and S. Ramakrishna, J. Am. Chem. Soc., 2018, 140, 13646-13653. 35 J. Bao, X. D. Zhang, B. Fan, J. J. Zhang, M. Zhou, W. L. Yang, X. Hu, H. Wang, B. C. Pan and Y. Xie, Angew. Chem. Int. Ed., 2015, 54, 7399-7404; Angew. Chem., 2015, 127, 7507-7512.

36 H. Yuan, J. T. Li, W. Yang, Z. C. Zhuang, Y. Zhao, L. He, L. Xu, X. B. Liao, R. Q. Zhu and L. Q. Mai, ACS Appl. Mater. Interfaces, 2018, 10, 16410-16417.

37 Y. X. Zeng, Z. Z. Lai, Y. Han, H. Z. Zhang, S. L. Xie and X. H. Lu, Adv. Mater., 2018, 30, 1802396.

38 Y. C. Wang, T. Zhou, K. Jiang, P. M. Da, Z. Peng, J. Tang, B. A. Kong, W. B. Cai, Z. Q. Yang and G. F. Zheng, Adv. Energy Mater., 2014, 4, 140069616.

39 W. J. Xu, F. L. Lyu, Y. C. Bai, A. Q. Gao, J. Feng, Z. X. Cai and Y. D. Yin, Nano Energy, 2018, 43, 110-116.

40 S. Zhang, P. Kang and T. J. Meyer, J. Am. Chem. Soc., 2014, 136, 1734-1737.

41 L. Xu, Q. Q. Jiang, Z. H. Xiao, X. Y. Li, J. Huo, S. Y. Huang and L. M. Dai, Angew. Chem. Int. Ed., 2016, 55, 5277-5281; Angew. Chem., 2016, 128, 5363-5367.

42 J. J. Wu, R. M. Yadav, M. J. Liu, P. P. Sharma, C. S. Tiwary, L. L. Ma, X. L. Zou, X. D. Zhou, B. I. Yakobson, J. Lou and P. M. Ajayan, ACS Nano, 2015, 9, 5364-5371.

43 Y. L. Ge, K. Kan, Y. Yang, L. Zhou, L. Q. Jing, P. K. Shen, L. Li and K. Y. Shi, J. Mater. Chem. A, 2014, 2, 4961-4969.

44 V. M. Jimenez, A. Fernandez, J. P. Espinos and A. R. Gonzalezelipe, J. Electron Spectrosc. Relat. Phenom., 1995, 71, 61-71. 
45 M. Ma, K. Zhang, P. Li, M. S. Jun, M. J. Jeong and J. H. Park, Angew. Chem. Int. Ed., 2016, 55, 11819-11823; Angew. Chem., 2016, 128, 11998-12002.

46 N. Kornienko, J. Resasco, N. Becknell, C. M. Jian, Y. S. Liu, K. Q. Nie, X. H. Sun, J. H. Guo, S. R. Leone and P. D. Yang, J. Am. Chem. Soc., 2015, 137, 7448-7455.

47 P. Z. Chen, T. P. Zhou, M. L. Chen, Y. Tong, N. Zhang, X. Peng, W. S. Chu, X. J. Wu, C. Z. Wu and Y. Xie, ACS Catal., 2017, 7, 7405-7411.
48 X. R. Li, J. L. Wei, Q. Li, S. S. Zheng, Y. X. Xu, P. Du, C. Y. Chen, J. Y. Zhao, H. G. Xue, Q. Xu and H. Pang, Adv. Funct. Mater., 2018, 28, 1800886.

49 L. Hua, Z. Y. Hui, Y. Sun, X. Zhao, H. Xu, Y. J. Gong, R. Y. Chen, C. Y. Yu, J. Y. Zhou, G. Z. Sun and W. Huang, Nanoscale, 2018, 10, 21006-21012.

50 H. Cheng, L. X. Ding, G. F. Chen, L. L. Zhang, J. Xue and H. H. Wang, Adv. Mater., 2018, 30, 1803694. 